\title{
Sensitivity of Asian Summer Monsoon precipitation to tropical sea surface temperature anomalies
}

\author{
Lei Fan ${ }^{1}$ Sang-Ik Shin ${ }^{2,3}$ - Zhengyu Liu ${ }^{4,5} \cdot$ Qinyu Liu ${ }^{1}$
}

Received: 9 May 2015 / Accepted: 4 January 2016 / Published online: 23 January 2016

(C) The Author(s) 2016. This article is published with open access at Springerlink.com

\begin{abstract}
Sensitivity of Asian Summer Monsoon (ASM) precipitation to tropical sea surface temperature (SST) anomalies was estimated from ensemble simulations of two atmospheric general circulation models (GCMs) with an array of idealized SST anomaly patch prescriptions. Consistent sensitivity patterns were obtained in both models. Sensitivity of Indian Summer Monsoon (ISM) precipitation to cooling in the East Pacific was much weaker than to that of the same magnitude in the local Indian-western Pacific, over which a meridional pattern of warm north and cold south was most instrumental in increasing ISM precipitation. This indicates that the strength of the ENSOISM relationship is due to the large-amplitude East Pacific SST anomaly rather than its sensitivity value. Sensitivity of the East Asian Summer Monsoon (EASM), represented by the Yangtze-Huai River Valley (YHRV, also known as the meiyu-baiu front) precipitation, is non-uniform across the Indian Ocean basin. YHRV precipitation was most sensitive to warm SST anomalies over the northern Indian Ocean and the South China Sea, whereas the southern
\end{abstract}

Lei Fan

fanlei@ouc.edu.cn

1 Key Laboratory of Physical Oceanography/Collaborative Innovation Center of Marine Science and Technology, Ocean University of China, Qingdao 266100, China

2 CIRES Climate Diagnostics Center, University of Colorado, Boulder, CO, USA

3 NOAA/Earth System Research Laboratory, Boulder, CO, USA

4 Department of Atmospheric and Oceanic Sciences, University of Wisconsin-Madison, Madison, WI, USA

5 Laboratory of Climate, Ocean and Atmospheric Studies, Peking University, Beijing, China
Indian Ocean had the opposite effect. This implies that the strengthened EASM in the post-Niño year is attributable mainly to warming of the northern Indian Ocean. The corresponding physical links between these SST anomaly patterns and ASM precipitation were also discussed. The relevance of sensitivity maps was justified by the high correlation between sensitivity-map-based reconstructed time series using observed SST anomaly patterns and actual precipitation series derived from ensemble-mean atmospheric GCM runs with time-varying global SST prescriptions during the same period. The correlation results indicated that sensitivity maps derived from patch experiments were far superior to those based on regression methods.

Keywords Sensitivity · Indian Summer Monsoon · East Asian Summer Monsoon · Precipitation · Tropical SST anomalies

\section{Introduction}

The Asian Summer Monsoon (ASM) is one of the most important monsoonal systems in the world and its variability can have profound socioeconomic consequences for over $40 \%$ of the world's population (Tao and Chen 1987; Wang et al. 2001; Wang and LinHo 2002; Ding and Chan 2005; Gadgil and Kumar 2006). There have been numerous studies concerning its variability and predictability (Rasmusson and Carpenter 1983; Webster and Yang 1992; Webster et al. 1998; Lau and Nath 2000; Ding and Chan 2005), which have established that long-term monsoonal variability is most likely controlled by slowly varying tropical sea surface temperature (SST) anomalies rather than by rapidly varying synoptic-scale instabilities (Charney and Shukla 1981; Yang and Lau 1998; Chang et al. 2000). Thus, 
Fig. 1 Percentage of SSTforced variance (shading) and "ensemble mean perfect model correlation skill" (contours) between the observations and the simulated ensemble mean [see Rowell (1998) for details] for 200-hPa height (upper panels) and precipitation (lower panels) anomalies in boreal summer (JJA), derived from a, c 16-member ensemble of NCAR-CCM3 and $\mathbf{b}, \mathbf{d}$ 24-member ensemble of MPIMECHAM5 simulations with global SST prescription during 1950-2004 (a) 200-hPa Height (CCM3)
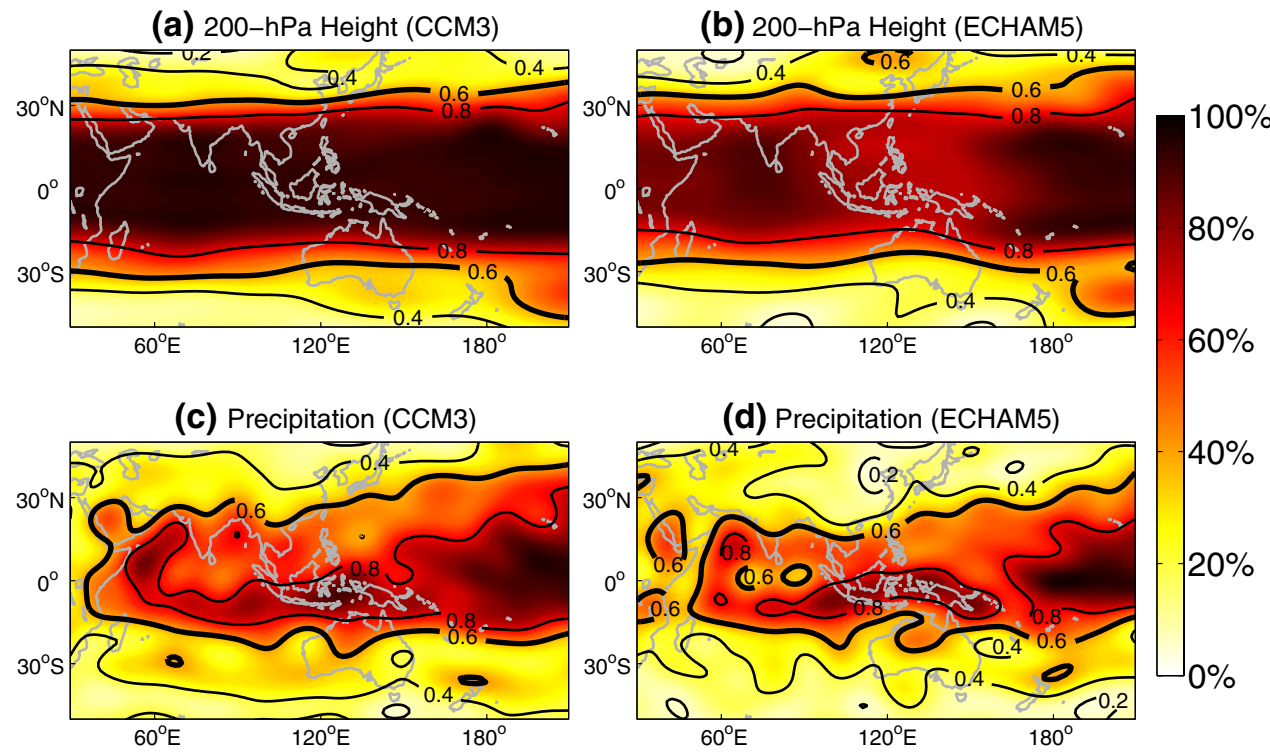

(d) Precipitation (ECHAM5)

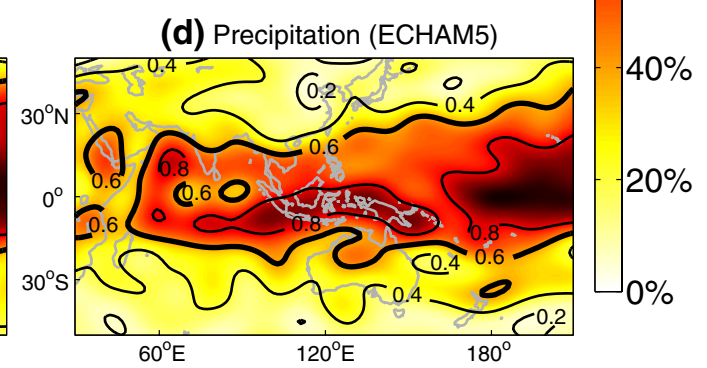

the climate research community is interested in addressing some remaining basic (but important) questions, such as the extent to which ASM variability is explained by tropical SST anomalies, and establishing which patterns of tropical SST anomalies are most instrumental in enhancing ASM precipitation.

Some ideas can be obtained by estimating the potential predictability of the ASM when provided with SST forcing. Figure 1 shows the predictability of 200-hPa height and precipitation, estimated by applying the analysis of variance (ANOVA; Rowell et al. 1995; Rowell 1998) to ensemble simulations of atmospheric general circulation models (GCMs) with a prescription of observed global SST (1950-2004; also known as GOGA runs). Ensemble simulations of two atmospheric GCMs were used for cross validation. These two models were the Max Planck Institute for Meteorology (MPIM) ECHAM5 (Roeckner et al. 2003) and the National Center for Atmospheric Research Community Climate Model version 3 (NCAR-CCM3; Kiehl et al. 1998), and their ensemble sizes were 24 and 16, respectively (see Sect. 2 for further description of the models). In Fig. 1, the ratio of SST-forced atmospheric variability to the total (shading) and the correlation skills (contours) during boreal summer is shown to highlight the potential predictability. In general, predictability is better in the tropics than in the extratropics. The correlation skills in the tropics are $>0.8$ for $200-\mathrm{hPa}$ height (Fig. 1a, b), indicating that its predictability is dominated by SST. The correlation skills for precipitation over the ocean, maritime continent, India, and Indochina Peninsula are $>0.6$, indicating that the predictability of precipitation over these regions is also determined largely by SST anomalies (Fig. 1c, d). In the extratropics, the SST-forced variability of precipitation explains about $15-30 \%$ of the total, providing an upper bound for the predictability of SSTforced precipitation.

This significant role of the tropical SST anomalies in tropical climates and their variability has inspired many studies of the relationship between the tropical SST anomalies and ASM variability. It has been established that the ASM comprises two subcomponents: the Indian Summer Monsoon (ISM; also referred to as the South Asian Summer Monsoon in the literature) and the East Asian Summer Monsoon (EASM) (Tao and Chen 1987; Wang and LinHo 2002; Ding and Chan 2005), which are relatively independent while interacting. The ISM, represented by all Indian rainfall (Parthasarathy et al. 1992), has been recognized as correlating negatively with remote SST anomalies over the eastern tropical Pacific associated with ENSO (Rasmusson and Carpenter 1983; Webster and Yang 1992; Zhou et al. 2009). This teleconnection is established through the displacement of the Walker circulation and the associated changes in convection over India (Webster and Yang 1992; $\mathrm{Wu}$ et al. 2012). For EASM precipitation, it is acknowledged that variability of the low-level circulation, i.e., the anomalous anticyclone/cyclone over the western tropical North Pacific (Wang et al. 2000, 2008; Li and Wang 2005), is the main cause of increased/decreased precipitation over the subtropical monsoon front (or meiyu-baiu front), which is also known as the Yangtze-Huai River Valley (YHRV) area. The abnormal anticyclonic circulation in summer is maintained by basin-wide warming of the Indian Ocean in response to El Niño (Yang et al. 2007; Li et al. 2008; Xie et al. 2009), local cooling in the western North Pacific in early summer (Nitta 1987; Huang and Sun 1992; Lu 2001; $\mathrm{Wu}$ et al. 2010), and cooling in the central tropical Pacific in late summer (Weng et al. 2011; Fan et al. 2013; Xiang et al. 2013). 
Fig. 2 Correlation map between a ISM precipitation and SSTs and b YHRV precipitation and SSTs. Results are calculated for summertime based on the observational data from 1948-2011. The values of 0.25 and 0.32 on the color bar denote the critical correlation value at the 90 and $95 \%$ confidence level, respectively. The target monsoon regions for ISM and YHRV are represented as red rectangles in (a) and (b), respectively. c Standard deviation of observed SSTs (HadISST; Rayner et al. 2003) and the center of 43 SST anomaly patches. For reference, the typical SST anomaly patterns of patches over the Indo-Pacific and the Atlantic are shown as contours. The contours are $0.1-1.7{ }^{\circ} \mathrm{C}$ with $0.4{ }^{\circ} \mathrm{C}$ intervals (a) Correlation between ISM precipitation and SST anomalies

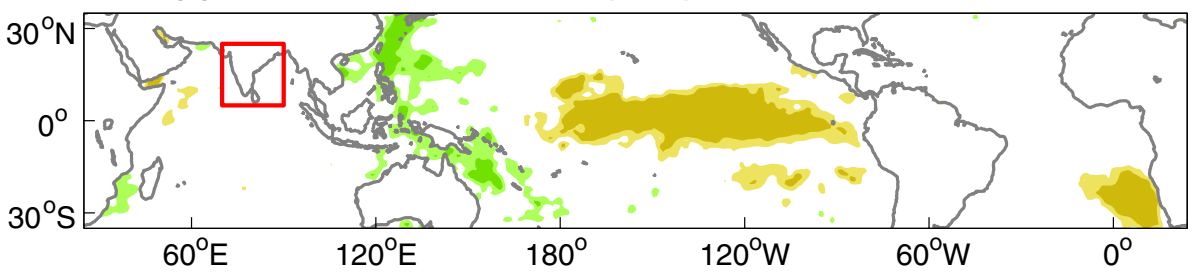

(b) Correlation between YHRV precipitation and SST anomalies

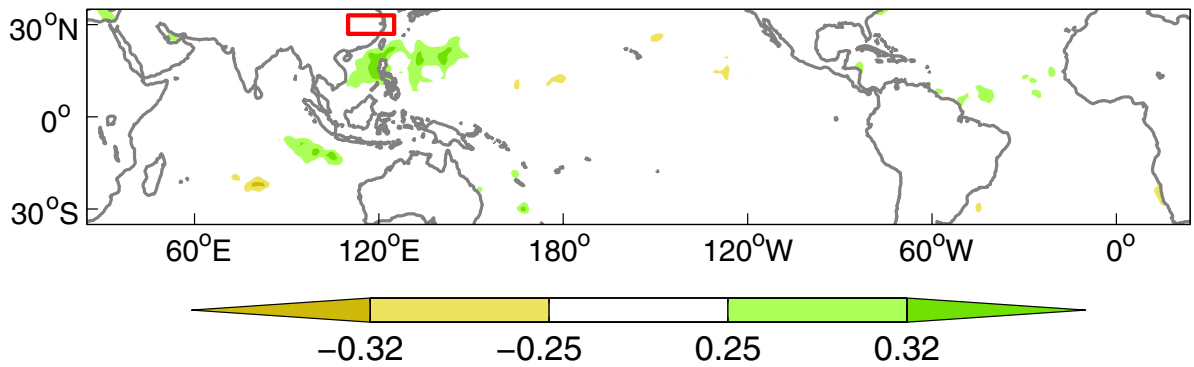

(c) SST standard deviation and patch locations

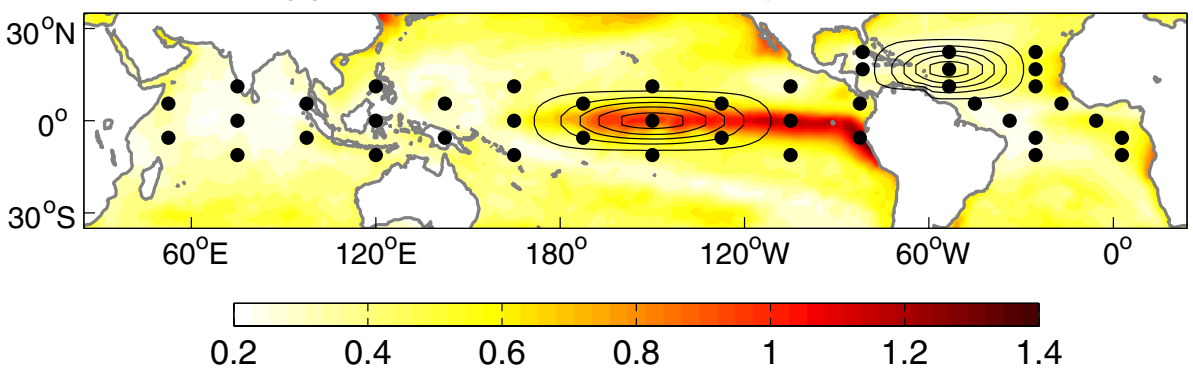

Over recent decades, seasonal climate prediction has advanced based on an improved understanding of the role of ENSO-related SSTs in global and regional climates (Latif et al. 1994; Kumar et al. 2005). However, considering that ENSO-related SST anomalies explain only about $50 \%$ of the total tropical SST variability, ${ }^{1}$ it is necessary to establish comprehensively the sensitivity of ASM precipitation to general SST anomalies in the tropics to improve its predictability further. To this end, one may consider the observed correlation between monsoonal precipitation and SST anomalies, as shown in Fig. 2a, b for ISM and EASM precipitation, respectively (see Sect. 2 for details of the dataset used). Interestingly, the $95 \%$ confidence test was failed in most parts of the tropical oceans. In addition to the well-established negative correlation between ISM precipitation and ENSO, ISM precipitation is also correlated with warm SST anomalies over the Western Pacific Warm Pool (Fig. 2a). Moreover, YHRV precipitation is associated more

\footnotetext{
1 This is based on the leading EOF of SSTs in the tropical Pacific (entire tropical oceans) explaining about $50 \%(30 \%)$ of the total variability.
}

closely with non-ENSO SST anomalies rather than with those of ENSO (Fig. 2b).

Caution should be exercised when interpreting the maps presented in Fig. 2a, b because correlation merely indicates statistical association rather than an actual dynamic link between monsoonal precipitation and tropical SST anomalies. A quantitative description of the sensitivity of monsoonal precipitation to SST anomalies across the entire tropical ocean has not been achieved. It is very difficult, if even possible, to estimate a "true atmospheric response" to SST anomalies in a particular region from observations because of the issue of the signal-to-noise ratio. This is because an observation has only a single realization with limited length; hence, SST anomalies over some regions might be too weak to generate sufficiently strong signals that could be separated from larger internal atmospheric noise. Moreover, SST anomalies over different regions are often inter-correlated (Klein et al. 1999) and thus, similarly, their corresponding atmospheric responses might be difficult to separate easily using observational data.

In this regard, the ensemble simulations using atmospheric GCMs provide a means with which to mitigate these restrictions. For a given ensemble size $N$, the ensemble mean can reduce the atmospheric internal variability by the 
factor of $\frac{1}{\sqrt{N}}$; thereby, robust SST-forced signals may be estimated. Additionally, in atmospheric GCM simulations, idealized SST anomalies can be prescribed over the region of interest only, to detect the separate influences in that region. Therefore, it is possible to obtain robust and comprehensive sensitivity maps using model ensemble simulations.

It has been reported previously that atmospheric GCMs have limited skill in rainfall prediction in the Asian monsoon region (Wang et al. 2005; Wu and Kirtman 2005); however, that limitation has been attributed more to their inherent lack of atmosphere-ocean coupling than to deficiencies within the models themselves (Wang et al. 2005). The purpose of this study was to diagnose the sensitivity of monsoonal rainfall to SST anomalies over each patch of the tropical region instead of performing a two-tier prediction. Moreover, to discern the climate sensitivity to an SST anomaly over a certain region, a determined steady SST anomaly over that region is required; however, current coupled GCMs are unable to capture the correct and steady SST anomaly patterns (Shin and Sardeshmukh 2010). Therefore, we used atmospheric GCMs despite their inherent limitations.

In this study, based on two atmospheric GCM models, we estimated quantitatively the sensitivity of ASM precipitation to tropical SST anomalies by analyzing a large ensemble of simulations where an array of idealized SST anomalies located over the entire tropical ocean was prescribed. The paper is organized as follows. The atmospheric GCMs, datasets, and an introduction to the methods used for sensitivity estimations are outlined in Sect. 2. The sensitivity maps as well as the associated physical links with ISM precipitation and YHRV precipitation are discussed in Sects. 3 and 4, respectively. Finally, a summary and concluding remarks are given in Sect. 5 .

\section{Models, datasets, and methodology}

To obtain a comprehensive sensitivity analysis of ASM precipitation to tropical SST anomalies, we performed a series of atmospheric GCM simulations forced by tropical SSTs. In those simulations, an array of steady localized SST anomaly patches in 43 locations was superimposed on the climatological annual cycle of global SSTs. The SSTs were obtained from the Hadley Centre Sea Ice and Sea Surface Temperature dataset (HadISST; Rayner et al. 2003). The locations and structures of these SST patches are shown in Fig. 2c, and the average magnitude of the prescribed SST anomalies at each patch location was $0.66{ }^{\circ} \mathrm{C}$. For each patch of SST anomalies, 20-ensemble member integrations of warm and an additional 20 of cold were performed for 25 months starting from October. The integration span of 25 months was sufficient to encompass the spin-up time and all four seasons. In this study, the linear part of the response to each patch was diagnosed as half the difference between the ensemble-mean atmospheric response to the warm and cold patch anomalies. For the measure of robustness, this study used two atmospheric GCMs: MPIM ECHAM5 (Roeckner et al. 2003) and NCAR CCM3 (Kiehl et al. 1998). Both models have T42 horizontal resolution (about $2.8^{\circ}$ longitude and latitude). The MPIM-ECHAM5 (NCAR-CCM3) is formulated in hybrid sigma-pressure coordinates with 19 (18) vertical levels.

Observational datasets were also used to assess the realism of the atmospheric GCMs in simulating the ASM circulation and precipitation. These comprised monthly 850$\mathrm{hPa}$ winds from the National Centers for Environmental Prediction (NCEP)/NCAR Reanalysis dataset (Kistler et al. 2001), monthly precipitation from the Climate Prediction Center (CPC) Merged Analysis of Precipitation (CMAP; Xie and Arkin 1997) datasets (1979-2011), and the CPC Precipitation Reconstruction over Land (PRECL) dataset (1948-2011).

To estimate the sensitivity (represented as $r$ ) of the monsoonal precipitation $p$ over a certain target region in a certain season to tropical SST forcing at M locations, it is simplest to derive the multiple linear regression between the $\mathrm{N}$-year precipitation time series $\boldsymbol{P}$ (e.g., an $\mathrm{N}$-component row vector) and the $\mathrm{N}$ time series of $\mathrm{M}$ forcings, i.e., an $\mathrm{M} \times \mathrm{N}$ matrix $\boldsymbol{T} \delta A$. The matrix $\boldsymbol{T}$ represents SST anomalies and the scalar $\delta A$ is the area element of each SST forcing. In this case, the target precipitation response $p$ (a scalar) to tropical SST forcing at a certain time can be represented as

$p=\boldsymbol{r}^{T}(\boldsymbol{T} \delta A)+e$,

where $\boldsymbol{r}$ is an M-component column vector representing the precipitation sensitivity to $\mathrm{M}$ forcings; the superscript ' $\mathrm{T}$ ' represents the transpose (same as below) and $e$ is the error due to the linear approximation and the limited length of samples. In regression analysis, error $e$ is minimized in the least square sense. This is the statistical way to estimate atmospheric sensitivity to SST anomalies. In practical applications, we usually perform univariate regression to diagnose the sensitivity pattern, and use stepwise regression to obtain the optimal regression equation for the reconstruction (or prediction) of precipitation.

Alternatively, as explained in previous studies (Barsugli and Sardeshmukh 2002; Barsugli et al. 2006; Shin et al. 2010), our patch experiments provided a dynamical means for the estimation of sensitivity under a linear assumption. The scalar area-averaged precipitation response $(p)$ to any single tropical SST anomaly pattern, represented as the 43-component vector $\boldsymbol{T} \delta A$, can be expressed as

$p=s^{\mathrm{T}}(\boldsymbol{T} \delta A)+\varepsilon$, 
where vector $\boldsymbol{s}$ is a 43 -component sensitivity and $\varepsilon$ is the error due to the linear approximation and the finite ensemble size of the patch experiments. To estimate sensitivity $\boldsymbol{s}$, we followed the procedures outlined in Barsugli and Sardeshmukh (2002). First, the raw precipitation sensitivity $s_{k}$ to the $k$ th patch $(k=1,2, \ldots, 43)$ was estimated by normalizing the area-averaged precipitation response $p_{k}$ with the intensity of the SST forcing over this patch. In discrete form,

$s_{k}=\frac{p_{k}}{\sum_{j}\left(T_{k, j} \cdot \delta A_{k, j}\right)}$,

where $T_{k, j}$ indicates the SST anomalies on the $j$ th grid within the $k$ th patch, $\delta A_{k, j}$ represents the area elements for the $j$ th grid point associated with the $k$ th patch, and $p_{k}$ can be obtained from the ensemble simulations of the $k$ th patch. The estimated raw sensitivity values were assigned to the geographical centers of the corresponding patches, and then thin-plate smoothing spline procedures (Bookstein 1989), based on the signal-to-noise ratio, were applied to minimize error $\varepsilon$. Here, we treated the error as SST-independent Gaussian random noise (Barsugli and Sardeshmukh 2002; Barsugli et al. 2006; Shin et al. 2010). For the display of the sensitivity maps, the values were scaled such that they represented the precipitation responses to a uniformly distributed $+1{ }^{\circ} \mathrm{C} \mathrm{SST}$ anomaly over a relatively large ocean area of $10^{6} \mathrm{~km}^{2}$.

The sensitivity vector may also be viewed as the optimal SST forcing for inducing ASM precipitation. This is because, among all possible SST forcing patterns that have the same root mean square (r.m.s.) amplitude, the pattern proportional to the sensitivity vector can maximize the precipitation response. In this sense, any of the observed SST EOF patterns could be considered possible subset realizations, but none of them need necessarily be the optimal pattern.

The patch-experiments method is based on the linear assumption that the influence of any large SST anomaly pattern on the atmosphere is equal to the linear combination of the influences of individual SST patches. To investigate the validity of this assumption, we linearly reconstructed the historical series of ASM precipitation anomaly based on the sensitivity map and SST observation, and compared the reconstructed series with the fully nonlinear time series of precipitation derived from the GOGA runs. The historical precipitation anomaly series was reconstructed as the weighted sum of 43 prescribed anomalies; in this process, the $k$ th precipitation anomaly was the response to the $k$ th patch of idealized SST anomaly, and its weight (i.e., the $k$ th weight) was determined by projecting the observed SST anomaly pattern on the $k$ th patch of SST anomaly. Obviously, the weighted sum could only be taken as the reconstructed precipitation anomaly if the superposition of all 43 ideal SST anomaly patches constituted a uniform SST anomaly pattern with $1{ }^{\circ} \mathrm{C}$ amplitude that spanned the entire tropical basin. However, that prerequisite was not met. Because of the superimposition of adjacent patches, the weighted sum was finally divided by an overlap factor to represent the reconstructed precipitation anomaly value (Barsugli and Sardeshmukh 2002).

The correlation value between the linearly reconstructed and the GOGA series is indicative of the degree to which the precipitation response was determined by tropical SSTs, and the degree to of the linearity of SST influencing ASM precipitation. If the sensitivity maps derived from the patch experiments adequately matched the GOGA results, the linear assumption would be proven acceptable, and the accuracy and robustness of the maps validated.

It was interesting to establish which of the two aforementioned methods (statistical regression analysis and dynamical patch experiments) provided the more accurate sensitivity of ASM precipitation to tropical SST forcings. Despite their formal equivalence, the sensitivities derived from the two methods could be different (Shin et al. 2010). Therefore, we also linearly reconstructed the precipitation series using the observed tropical SST patterns and the sensitivity pattern derived by the regression method, and compared the reconstructed series with the GOGA results, to test the validity of the regression-derived sensitivity maps. In building the regression model, we used stepwise regression, which can achieve the best precipitation reconstruction in the linear sense. In the stepwise regression, the selection of predictive variables (regions of SST) was performed using an automatic procedure based on the precipitation-SST correlations, taking the form of a sequence of F-tests. As the regression model should be assessed against a dataset not used to build the model (Bariffa et al. 1983; Jonathan and Goldberg 2001), we divided the data into a training period and a hindcast period, and calculated the correlation values (denoted in Fig. 5) over the hindcast period only. Better performance of the sensitivity maps derived from the patch experiments, in comparison with the regression-derived sensitivity maps, would imply that the sensitivity results derived from the patch experiments of this study were important.

\section{Sensitivity of ISM precipitation}

We derived maps of the sensitivity of the ISM and YHRV precipitation to tropical SST anomalies using both the statistical and the dynamical methods, within the limits of atmospheric GCM realism in simulating monsoonal precipitation and circulations. In general, models that simulate climatology more realistically tend to capture better interannual variability (Sperber and Palmer 1996; Sperber 1999). Therefore, we examined the realism of the 
atmospheric GCMs in simulating the climatological lowerlevel circulations and precipitation, as well as their interannual variability, over our domain of interest. In Fig. 3, the simulated summer (JJA) averages of the 850 -hPa winds and precipitation (Fig. 3b, c; shading) and standard deviations of precipitation (Fig. 3b, c; contours) are compared with the observational datasets (Fig. 3a). The model biases are also shown in Fig. 3d, e. The observational datasets used
Fig. 3 Summer averages (1979-2011) of 850-hPa winds (vectors, $\mathrm{m} \mathrm{s}^{-1}$ ), precipitation (shading; $\mathrm{mm} \mathrm{day}^{-1}$ ), and standard deviation of precipitation (contours, $\mathrm{mm} \mathrm{day}^{-1}$ ) for a observations, $\mathbf{b}$ ensemble mean of NCAR-CCM3, and c ensemble mean of MPIM-ECHAM5. d, e The differences between the simulation and observations for CCM3 and ECHAM5, respectively. In (d) and (e), the red (blue) contours (CI: $1 \mathrm{~mm} \mathrm{day}^{-1}$ ) denote positive (negative) values and zero lines are omitted
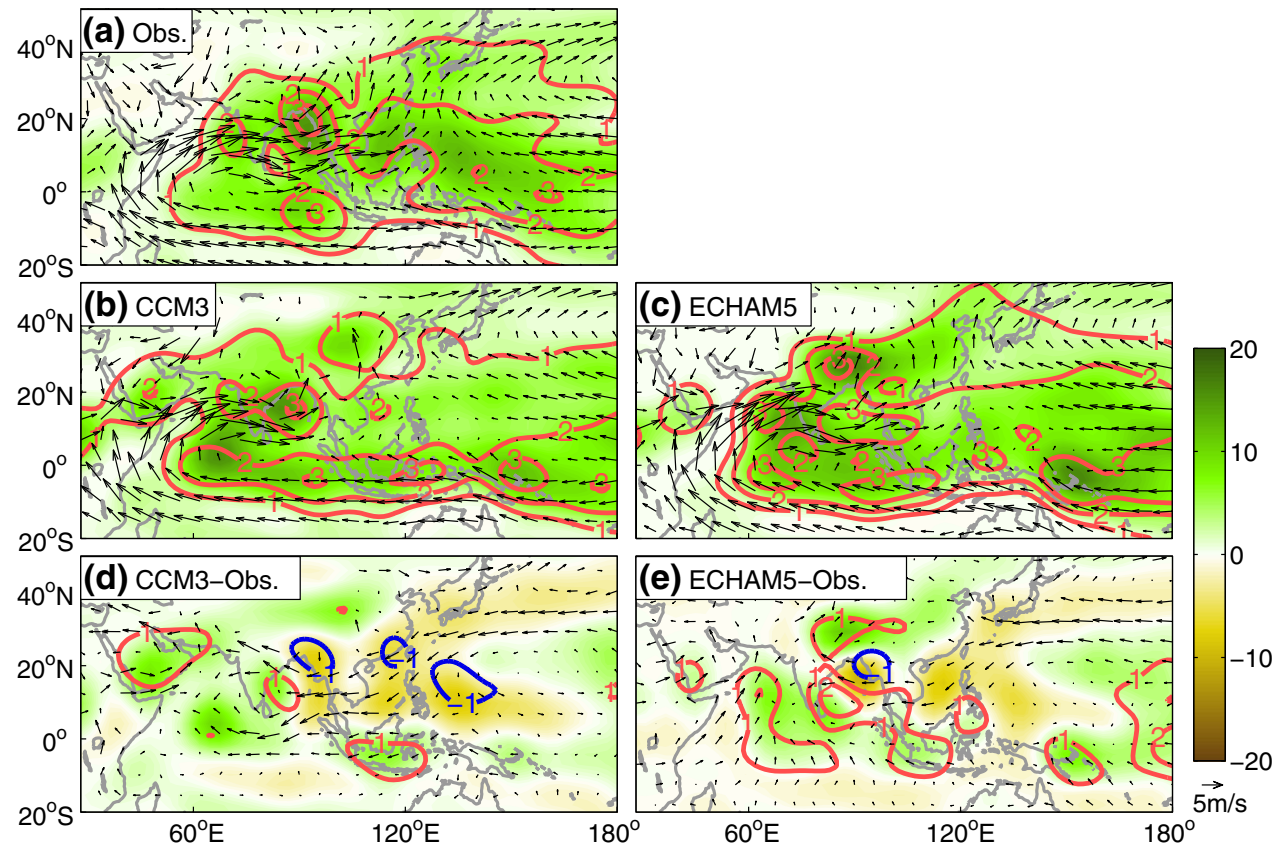

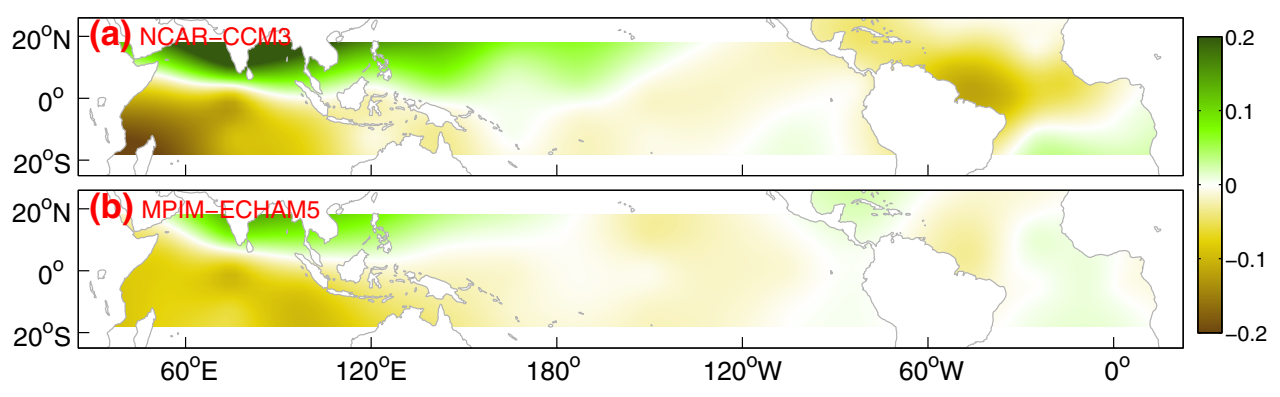

Fig. 4 Sensitivity maps of summertime (JJAS) Indian monsoon precipitation to tropical SST anomalies, derived from the patch experiments using a NCAR-CCM3 and b MPIM-ECHAM5. The sensitivity

values denote the ISM precipitation anomaly $\left(\mathrm{mm} \mathrm{day}^{-1}\right)$ in response to a $1{ }^{\circ} \mathrm{C} \mathrm{SST}$ anomaly distributed uniformly over an ocean area of $10^{6} \mathrm{~km}^{2}$

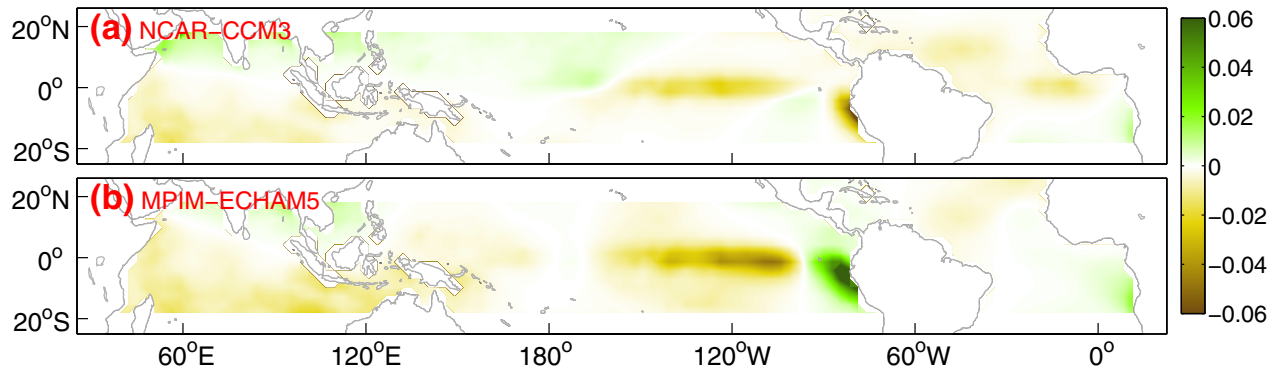

Fig. 5 Similar to Fig. 4 but the sensitivity maps are multiplied by the SST standard deviation shown in Fig. 2c 
here were the CMAP (Xie and Arkin 1997) for precipitation, during 1979-2011, and NCEP-NCAR Reanalysis (Kistler et al. 2001; Fig. 3a, b) for the 850-hPa winds during the same period.

As shown in Fig. 3, both the NCAR-CCM3 and the MPIM-ECHAM5 generally captured the essence of the ASM circulation system, except for a slight underestimation of the South China Sea-western Pacific convergence zone. Over the Indian Peninsula and nearby regions, both models produced a realistic simulation of the precipitation as well as its standard deviation. For the EASM, the simulated subtropical high was reasonable in terms of its strength and position, although the subtropical monsoon frontal precipitation (meiyu belt) was slightly underestimated (Fig. 3d, e) because of the weak southwesterly winds over the South China Sea (and hence the weak water vapor transport to the meiyu belt). The correlations between the patterns of simulated precipitation and the observations were 0.65 for MPIM-ECHAM5 and 0.73 for NCARCCM3. Overall, the monsoon climatology and its interannual variability were simulated reasonably well, providing assurance of our sensitivity maps derived dynamically from the patch experiments using the two models.

\subsection{Sensitivity maps}

Maps of the quantitative sensitivity of ISM precipitation to tropical SST anomalies, derived from the patch experiments using the NCAR-CCM3 and MPIM-ECHAM5 atmospheric GCMs, are shown in Fig. 4a, b, respectively. The two models yielded very similar sensitivity patterns (pattern correlation 0.77), although some discrepancies exist in their magnitudes and the detailed patterns over the tropical Atlantic basin. Both models were consistent in indicating that ISM precipitation is most sensitive to a meridional dipole pattern in the Indian-western Pacific Ocean; the warm (cold) SST anomalies in the north and cold (warm) SST anomalies in the south are favorable for increased (decreased) ISM precipitation. As regards the magnitude of the sensitivity value, unit SST forcing with a $1{ }^{\circ} \mathrm{C}$ anomaly distributed uniformly over a $10^{6} \mathrm{~km}^{2}$ area in the Indian Ocean caused an ISM precipitation rate of about $0.2 \mathrm{~mm} /$ day. This meridional pattern helps explain why the decrease of the observed meridional SST gradient over the Indian Ocean has weakened ISM precipitation since the 1950s (Chung and Ramanathan 2006). By contrast, the map of the correlation between ISM precipitation and SST (Fig. 2a) shows much less information in the Indian Ocean because the correlation coefficients over most of the area were not significant.

Over the eastern tropical Pacific, both sensitivity maps in Fig. 4 indicate a negative relationship between ISM precipitation and SST anomalies, which agrees with the well-known observed ENSO-ISM relationship (Rasmusson and Carpenter 1983; Wu et al. 2012). This connection operates through the modulation of the Walker circulation, which leads to suppressed convection and reduced precipitation over the Indian Peninsula (see Sect. 3b). It is noteworthy that both models (Fig. 4a, b) show sensitivity values over the eastern Pacific that are smaller than over the Indian-western Pacific Ocean. This means the ISM precipitation response to local SST anomalies is larger compared with the remote SST anomaly in the eastern Pacific of the same magnitude. To interpret this, it is important to distinguish between the sensitivity of precipitation and the actual precipitation response to tropical SST anomalies. Note that the regions of large forcing (large amplitude of SST anomaly) are not always regions of large "sensitivity." The actual ISM precipitation response is the "product" of these sensitivities and forcing, where the forcing is represented as the surface integral of SST anomalies over a certain area. Figure 5 shows the map of such sensitivity multiplied by the SST standard deviation shown in Fig. 2c. We can see that the equatorial eastern Pacific SSTs for both models are more remarkable than shown in Fig. 4, which occurs because of the large magnitude of the eastern Pacific SST. Hence, the strength of the ENSO-ISM relationship may be attributed to the large ENSO amplitude rather than to the sensitivity. Considering the largest SST variability, the eastern tropical Pacific remains an important contributor to ISM precipitation changes.

The sensitivity patterns derived from the patch experiments (Fig. 4) differ from those derived using the simple linear regression or correlation methods with simulated precipitation and SST data from the GOGA ensemble mean (see Fig. 6a). The correlation map presented in Fig. 6a is similar to the correlation map (Fig. 2a) of the observations; it also failed to capture the dominant role of the northsouth SST gradient in forcing ISM precipitation. Thus, one may wonder whether the map of Fig. 6a or Fig. 4a is most representative of the sensitivity of ISM precipitation to tropical SST anomalies. As mentioned before, one way to measure the accuracy of the sensitivity map is to linearly reconstruct the historical series of ISM precipitation anomalies, based on the observational SSTs and the two kinds of sensitivity maps, and then to compare the reconstructed precipitation series with the actual time series of precipitation responses from GOGA. The two reconstructed series are shown in Fig. 7, where the blue line indicates the reconstruction based on the sensitivity map derived from the patch experiments (Fig. 4a) and the yellow line represents the reconstruction based on the regression-derived sensitivity map (Fig. 6a). Both reconstructions are compared with the standard series (red line) from a 24-member GOGA ensemble mean. The correlation between the standard series from GOGA and the reconstructed series using 
(a) Correlation between ISM precipitation and SST anomalies

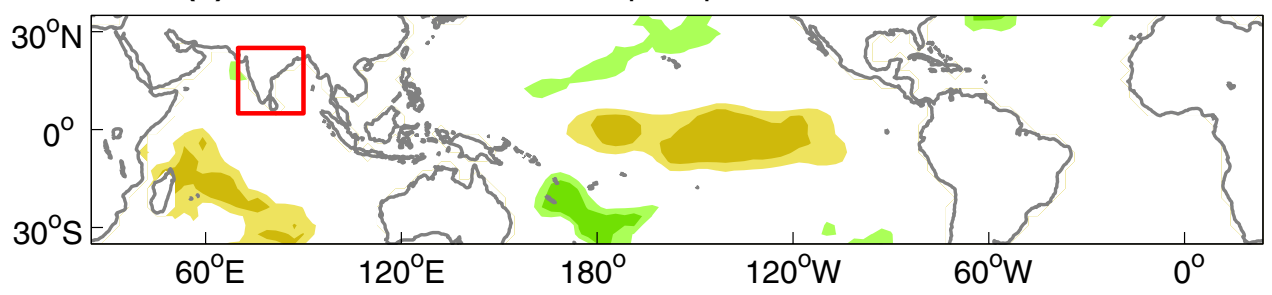

(b) Correlation between YHRV precipitation and SST anomalies

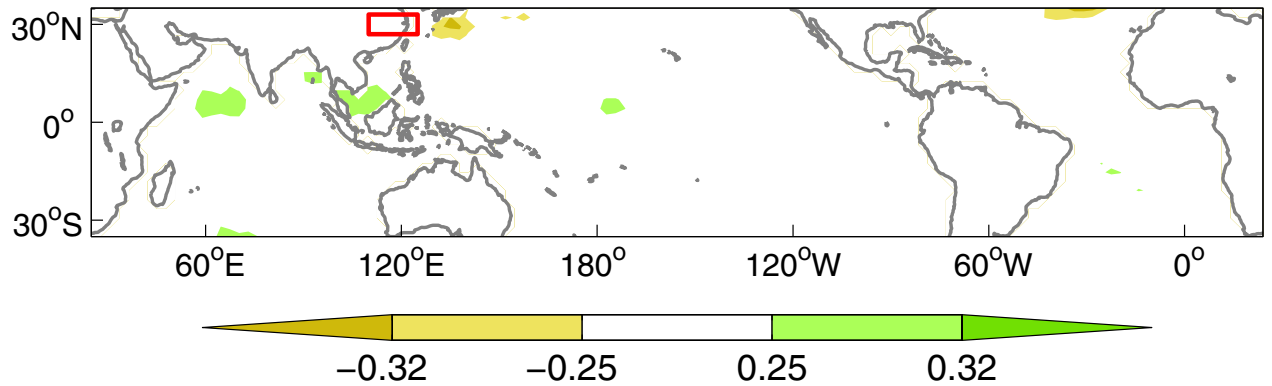

Fig. 6 As in Fig. 2a, b but the precipitation data are from the CCM3 GOGA ensemble mean when calculating the correlation

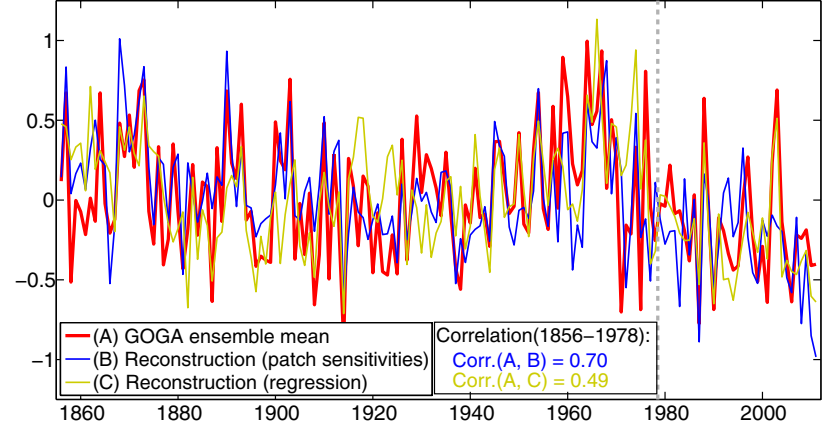

Fig. 7 Linearly reconstructed ISM precipitation series using patchexperiment (blue line) and step-wise-regression models (yellow line; see text for details). Both reconstructed series are compared with the standard series (red line), i.e., the precipitation anomaly series from the ensemble mean of the NCAR-CCM3 GOGA simulations. The training period of the regression model was 1979-2011, and the correlation coefficients were calculated only for the test period 18561978. The dashed gray line denotes the boundary separating the test and training periods

the patch experiments indicates the extent to which ISM precipitation is determined by the tropical SST anomalies and the extent to which the linear assumption is applicable. Furthermore, the comparison of the correlations of the standard series with both reconstructions can reveal which method produces the most reliable sensitivity results. For a fair comparison, the correlation values were calculated in both cases for the test period of 1856-1978, because the training period of the regression was 1979-2011.

It can be seen from Fig. 7 that the correlation between the patch-experiment-based linear reconstruction and the standard series is 0.7. The reasonably good agreement between the two series implies that ISM precipitation is determined mainly by tropical SSTs. Furthermore, it suggests that the ISM precipitation response to tropical SST anomalies is approximately linear, since the linear combination of tropical patch responses largely explains the fully nonlinear response to global SST anomalies. This high correlation also indicates the sensitivity map in Fig. $4 \mathrm{a}$ is an accurate measure of ISM sensitivity to tropical SST forcings. In contrast, the correlation between the regression-based reconstruction and the actual series is 0.49 , indicating the sensitivity pattern in Fig. $6 \mathrm{a}$ is not as accurate as in Fig. 4a, i.e., the patch-experiment method is superior to the regression method. We suspect that the poorer performance of the regression method was mainly due to the weak observed SST variability over the Indian Ocean. In general, it is more difficult to determine the true sensitivity from observation (which is a single realization) over the regions of weak SST variability because of the small signal-to-noise ratio. However, our atmospheric GCM integrations used a large number of ensemble members and relatively large SST forcing, which allowed the discerning of those weak influences of small-amplitude SSTs. When such weak but correct influences are incorporated in the construction of the ISM rainfall anomalies series (blue line in Fig. 7), the results can be improved noticeably. In the stepwise regression model, however, those factors may easily be rejected because of their low correlation values. This could be the reason why the patchsensitivity-based reconstruction outperformed the regression method in Fig. 7. 


\subsection{Physical links}

As mentioned in Sect. 2, among all possible SST forcing patterns that have the same r.m.s. amplitude, the one that is proportional to the sensitivity pattern can maximize the precipitation response, so it can be viewed as the theoretically optimal SST pattern for causing intense ISM precipitation. To understand how the optimal SST pattern (as in Fig. 4) enhances ISM precipitation, we constructed the atmospheric responses (precipitation, 200-hPa geopotential height, and $850-\mathrm{hPa}$ winds) to the SST anomaly of the same pattern as the sensitivity map, but normalized with an r.m.s. amplitude of $1{ }^{\circ} \mathrm{C}$. These atmospheric responses were determined as the weighted sum of the responses to individual patch results, where the weight was proportional to the integrated SST anomaly within each patch. Here, we chose two tropical ocean basins: the tropical Indian-western Pacific Ocean and the eastern tropical Pacific Ocean separated by the dateline, because they not only represent the epicenters of sensitivity shown in Fig. 4, but are also the regions where the two models produce consistent sensitivity patterns. The same procedures were applied for both the NCAR-CCM3 and the MPIM-ECHAM5 GCMs and virtually similar results were obtained. Thus, in Fig. 8, we show only the atmospheric responses determined from MPIM-ECHAM5.

The physical mechanism for the response of ISM precipitation to Indian Ocean SST anomalies is reasonably straightforward (Fig. 8a). The SST pattern of a warm north and a cold south (see Fig. 4b for the SST pattern)

(a) Indian-Western Pacific SST

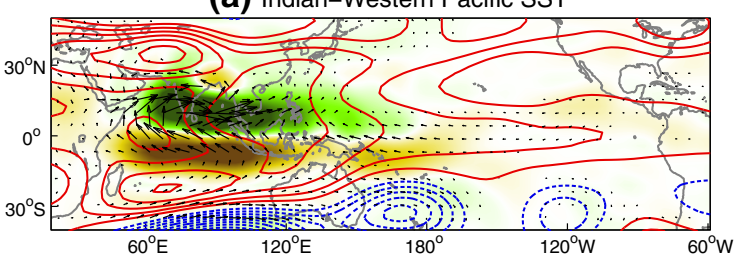

(b) Eastern Pacific SST

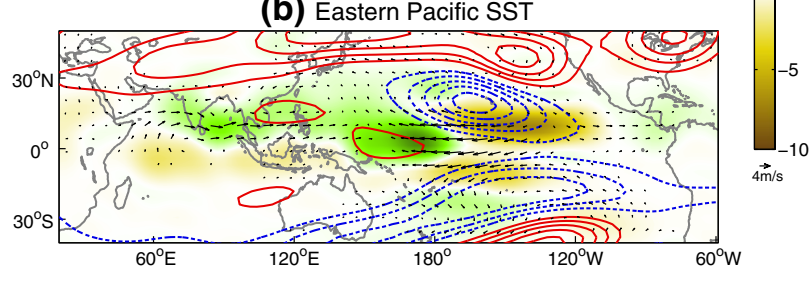

Fig. 8 Linearly reconstructed responses of precipitation (shading; $\mathrm{mm} \mathrm{day}{ }^{-1}$ ), 850-hPa winds (vectors; $\mathrm{m} \mathrm{s}^{-1}$ ), and 200-hPa geopotential height (contours; $\mathrm{m}$ ) to the scaled optimal SST forcing for ISM precipitation (Fig. 4b) over the a Indian-western Pacific and the $\mathbf{b}$ eastern Pacific basins separated by the dateline. The results are based on the MPIM-ECHAM5 patch experiments. The contour interval is $10 \mathrm{~m}$ and zero contours are suppressed. The red solid (blue dashed) lines indicate positive (negative) values intensifies the cross-equatorial summer monsoonal flow, and enhances the moisture transport to cause heavy rainfall over the Arabian Sea, Bay of Bengal, and Indian Peninsula. The atmospheric responses over the Indian Ocean can be explained as a Gill-type response to an antisymmetric heating anomaly about the equator (Gill 1980). In general, a warm (cold) SST anomaly in the tropics causes in situ positive (negative) geopotential height anomalies at upper levels. However, the joint effect of warm north and cold south Indian Ocean SST anomalies on the 200-hPa geopotential height is all positive over the Indian Ocean (Fig. 8a). This is because the climatological SSTs over the Indian Ocean during boreal summer are much warmer in the north than in the south. Thus, the resultant convection anomaly, depending upon the total SSTs, is dominated by the warming in the northern Indian Ocean.

As for the atmospheric responses (Fig. 8b) to the eastern tropical Pacific parts (to the east of the dateline) of the optimal SST pattern (see Fig. 4b for the SST pattern), the negative SST anomalies over the eastern tropical Pacific intensify the Walker circulation. Consequently, subsidence is intensified over the eastern tropical Pacific, while the convection is intensified over the Indo-Pacific Warm Pool, which causes surface westerly anomalies over the South China Sea and the northern Indian Ocean. These westerly anomalies bring enhanced moisture transport that increases ISM precipitation.

\section{Sensitivity of EASM precipitation}

\subsection{Sensitivity maps}

The sensitivity of YHRV precipitation to tropical SSTs is shown in Fig. 9. The two models yielded consistent patterns of sensitivity over the Indian Ocean and the South China Sea. The positive SST anomalies in the northern Indian Ocean and the South China Sea are particularly effective in bringing above-normal YHRV precipitation. It is noteworthy that the southern Indian Ocean, though with comparatively small magnitude in strength, has an opposite effect to that of the northern Indian Ocean. This implies the significant role of the northern Indian Ocean in the capacitor effect of the basin-wide warming of the Indian Ocean on the EASM (Yang et al. 2007; Li et al. 2008; Xie et al. 2009). It should be borne in mind that the theoretically optimal forcing pattern is not necessarily one of the common SST EOF patterns, while the identified optimal forcing pattern can help improve our understanding of the basic questions and provide some hints regarding precipitation prediction.

To investigate the relevance of the sensitivity map shown in Fig. 9, we reconstructed the anomalous YHRV 
Fig. 9 As in Fig. 4 but for the summertime (JJ) sensitivity of YHRV precipitation to tropical SST anomalies derived from NCAR-CCM3 and b MPIMECHAM5 the patch experiments using a
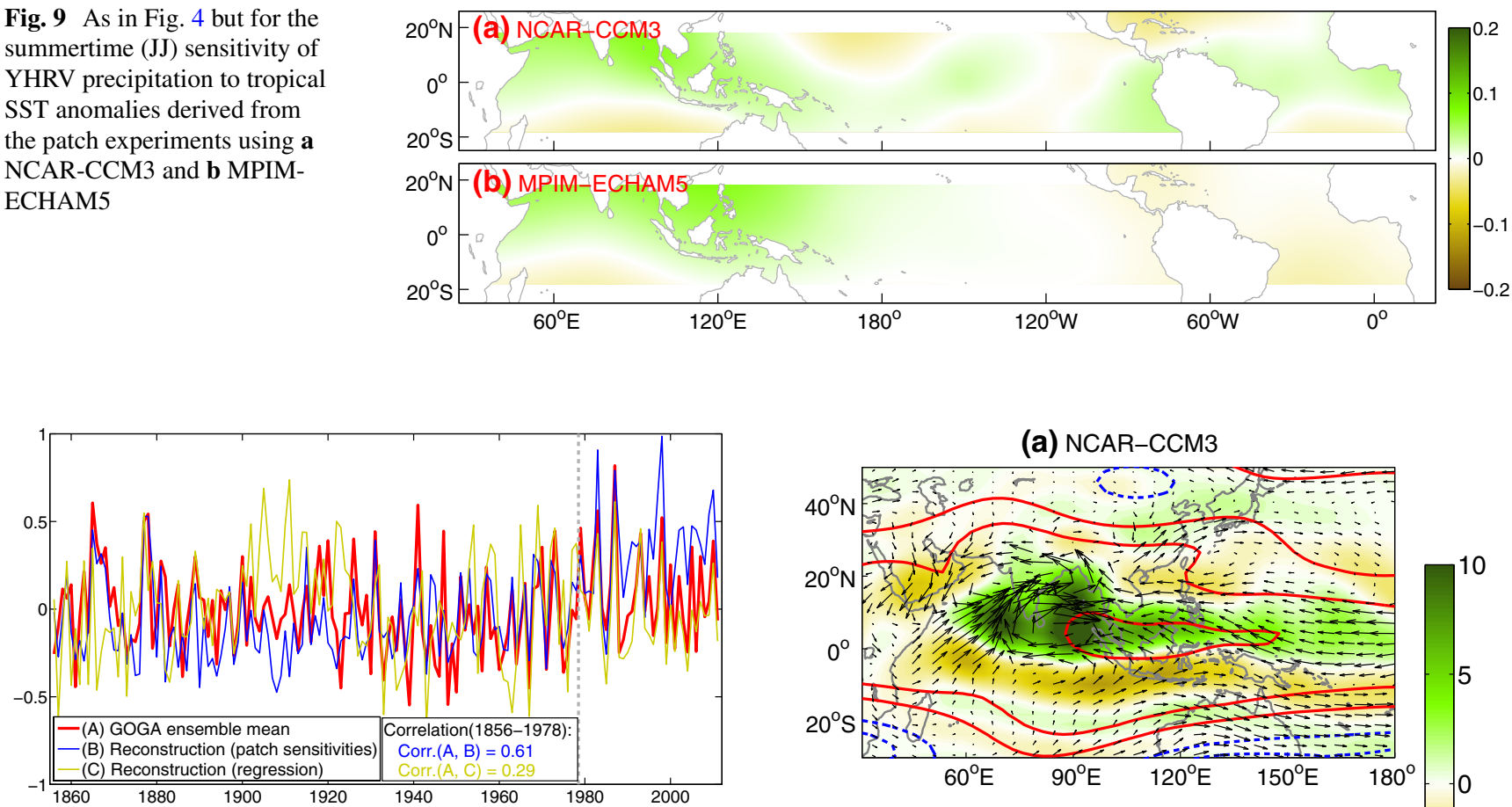

Fig. 10 As in Fig. 7 but for the linearly reconstructed time series of YHRV precipitation anomaly

precipitation time series using the sensitivity map derived from the patch experiments (blue line, Fig. 10) and the stepwise-regression-based sensitivity map (yellow line, Fig. 10), and compared both series with the actual series derived from the GOGA runs (red line, Fig. 10). Here, we assessed the accuracy of the sensitivity map using the NCAR-CCM3 simulations for which long-term (18562011) GOGA simulations were available. The correlation coefficient between the patch-experiment-based reconstruction and the actual nonlinear precipitation series was 0.61 . This value is passable but not as high as that achieved for the ISM precipitation in Fig. 7. This implies that the nonlinear or extratropical factors might have a greater effect on EASM precipitation than on ISM precipitation. Nevertheless, the value of 0.61 is much higher than the value of 0.29 achieved for the regression-based sensitivity map (Fig. 6b), confirming the validity of the sensitivity maps derived from the patch experiments, shown in Fig. 9. The reason for this is similar to the ISM case elaborated in Sect. 3.1.

\subsection{Physical links}

How the hypothetical SST anomaly pattern shown in Fig. 9 was linked to the YHRV precipitation? To examine this, we linearly reconstructed the precipitation, $850-\mathrm{hPa}$ winds, and 200-hPa geopotential height responses to the SST anomalies over the Indian-western Pacific Ocean region (west of (a) NCAR-CCM3

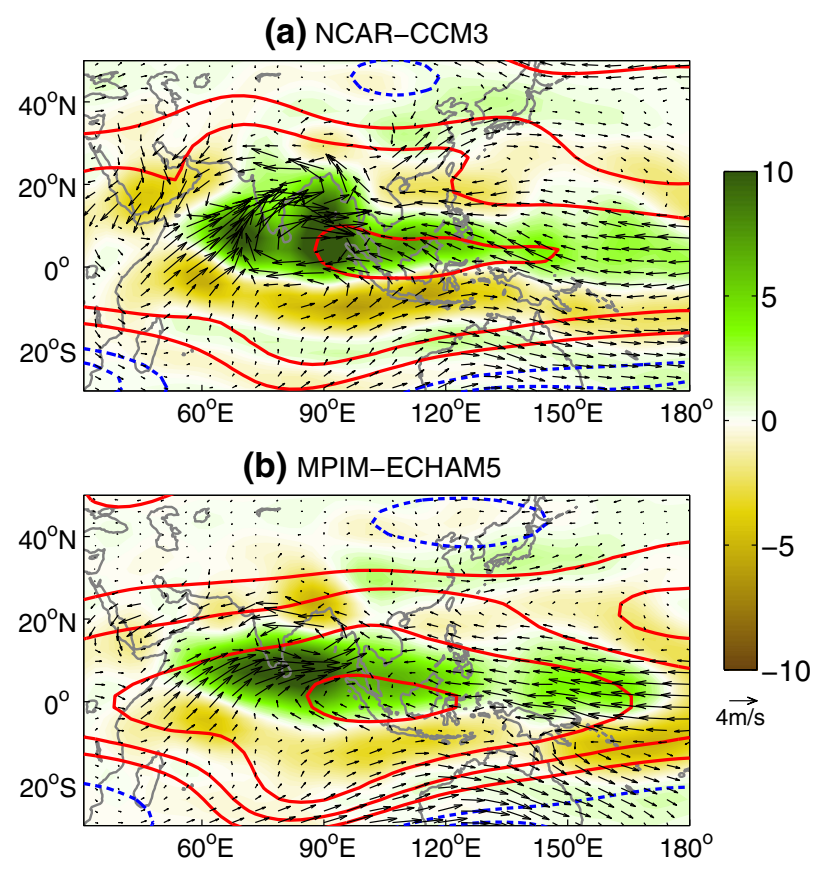

Fig. 11 Linearly reconstructed responses of precipitation (color shading), $850-\mathrm{hPa}$ winds (vectors), and $200-\mathrm{hPa}$ height (contours) to the scaled optimal SST pattern in the Indian-western Pacific (west of $130^{\circ} \mathrm{E}$, Fig. 9) for maximizing YHRV precipitation using a the NCAR-CCM3 and b the MPIM-ECHAM5 patch experiments. The contour interval is $20 \mathrm{gpm}$, and zero lines are suppressed. The red solid (blue dashed) lines denote positive (negative) height anomalies

$150^{\circ} \mathrm{E}$ ), where the two models yielded similar sensitivity patterns. Again, the pattern of the hypothetical SST anomalies is the same as in the sensitivity maps shown in Fig. 9a, b but with the r.m.s. amplitude scaled to be $1{ }^{\circ} \mathrm{C}$.

Figure 11 shows that the two models yielded very similar atmospheric responses to their respective SST anomalies. Locally, the upper-level (200-hPa) ridge developed in response to the Indian-western Pacific Ocean warming. Over the Indian Ocean, this upper-level ridge was accompanied by strengthened westerly winds in the lower troposphere. The intense warming over the northern Indian Ocean led to a lower-tropospheric anticyclonic anomaly over the northwestern Pacific (Xie et al. 2009). The anomalous easterlies on the southern flank of the anticyclone and 
the anomalous westerlies from the northern Indian Ocean converge over the Indochina Peninsula, which enhanced the precipitation over the northern Indian Ocean. Meanwhile, the strengthened southwesterly monsoonal winds on the northwest flank of the anticyclone increased the moisture transport from the western Pacific to the YHRV region, causing the intensified precipitation over the subtropical monsoon frontal region extending from the YHRV region to Korea and Japan. This is how the optimal forcing pattern (in Fig. 9) enhanced YHRV rainfall via the anomalous monsoon circulation.

\section{Summary and concluding remarks}

In this study, based on two atmospheric GCMs (NCARCCM3 and MPIM-ECHAM5), we quantitatively estimated the comprehensive sensitivity of ASM precipitation to tropical SST anomalies by performing ensemble simulations with the prescription of an array of 43 theoretically steady localized SST anomaly patches over the tropics. The results are summarized as follows.

Both models yielded reasonably consistent sensitivity patterns for ISM and YHRV precipitation. It was established that ISM precipitation is most sensitive to a meridional dipole of SST anomalies over the Indian and western tropical Pacific oceans, with warming in the north and cooling in the south being most favorable for ISM precipitation. This meridional gradient of SST anomalies intensifies the cross-equatorial monsoonal flows, thereby increasing moisture transport to the Indian Peninsula. ISM precipitation is also sensitive to SST anomalies over the eastern tropical Pacific, but to a lesser extent; the cold (warm) SST anomalies over the eastern tropical Pacific modulate the Walker circulation by causing convection (subsidence) over the ISM region, which increases (decreases) the precipitation. For the EASM, the above-normal YHRV precipitation is most sensitive to warm SST anomalies over the northern Indian Ocean and the South China Sea; it is also sensitive to cold SST anomalies in the southern Indian Ocean but to a lesser degree. In response to these SST anomalies, an anomalous anticyclone develops over the northwestern Pacific, which increases moisture transport to the YHRV region.

The patch-experiment method was based on the linear assumption that the influence of any large SST anomaly pattern on the atmospheric object of study is equal to the linear combination of the influences of individual SST patches. To validate this assumption and verify the degree of accuracy of the sensitivity maps, we reconstructed the historical series using the observed SST pattern and the sensitivity maps derived from the patch experiments, and compared the reconstruction with the standard precipitation anomaly series from the ensemble mean of the fully nonlinear GOGA simulations. The reasonably high correlation values between the two series demonstrated that the linear assumption was acceptable, especially for ISM precipitation. The high correlation also validated the accuracy of the sensitivity maps. To support the superiority of these sensitivity maps, we also estimated a formally equivalent sensitivity with the regression method using the GOGA ensemble mean data. Compelling evidence suggested that the sensitivity maps obtained from the patch experiments were accurate and superior to those obtained from the regression analysis. The poor skill of the regression might be attributable to its inability to capture the effects of relatively weak but critical SST anomalies. Conversely, our ensemble patch runs, with a relatively large SST anomaly, are better able to resolve the correct atmospheric response to the SST forcings, especially over the tropical regions of weak SST variability.

Although some of the above results agree with earlier studies, our study highlighted a number of new findings:

1. This study derived quantitative maps of the sensitivity of ASM precipitation to tropical SST anomalies based on a series of patch experiments, alleviating the signal-to-noise ratio problem in observational study. The patch-experiments method with SST prescription could obtain the separate influences of each SST anomaly patch. SST anomaly patterns similar to the sensitivity patterns can be viewed as the optimal forcing patterns in inducing ASM precipitation. The optimal patterns were different from the common EOF patterns of SST and they might not occur sufficiently often in the real world to be of value.

2. Regions of large forcing are not always the regions of large sensitivity. The ISM is more sensitive to local SST anomalies than to the remote eastern Pacific SST anomaly of the same magnitude, indicating that the strength of the well-known ENSO-ISM relationship is attributable more to ENSO amplitude than to the sensitivity.

3. For EASM precipitation, the present results revealed that its sensitivity to Indian Ocean SST is not uniform throughout the basin, but that the northern and southern parts of the Indian Ocean have contrasting effects on the EASM. This implies that the strengthened EASM, associated with basin-wide warming of the Indian Ocean in the post-Niño year, is attributable mainly to the northern Indian Ocean.

The high correlation skills of the monsoon hindcasts, shown in Figs. 7 and 10, raise the possibility that the sensitivity maps, with a tropical SST forecast derived from other statistical and/or numerical modeling means, could 
(a) ISM precipitation

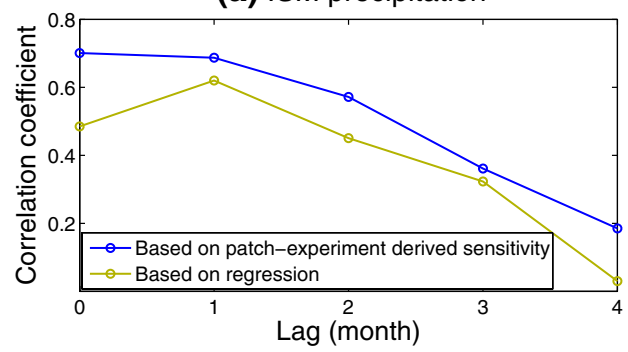

Fig. 12 Correlation between the predicted precipitation time series and the actual GOGA ensemble means using NCAR-CCM3. It is a similar reconstruction to Figs. 7 and 10 but the SST leads the sensitivity pattern by $0-4$ months. The blue (yellow) lines use the patch-

be used to obtain the seasonal monsoon outlook. Alternatively, the patch-based sensitivity maps, although indicating a simultaneous relation, could still be used for monsoon predictions, if the persistence of the tropical SST anomalies provided sufficient prediction skill. In this case, the prediction procedure would be the same as in the linear reconstruction used in Figs. 7 and 10, except for the timing of the SST anomalies. For example, to predict the ISM precipitation anomalies in July, we would use the tropical SST anomalies from April (lag 3) to July (lag 0) and the ISM sensitivity maps in June-August. Some preliminary results are shown in Fig. 12 for the correlation between the actual (GOGA-derived), predicted for the ISM (Fig. 12a), and YHRV precipitation anomalies (Fig. 12b). The results are presented for both patch-experiment-based (blue lines) and regression-based (yellow lines) methods, and it is clear that the former displays better skill than the latter for almost all lags. For the patch-experiment-based method, the correlation remains $>0.6$ for the 2 -month lead ISM prediction, indicating that our prediction procedure does provide the first outlook of the ISM precipitation. The YHRV precipitation is comparatively less predictable than ISM precipitation. Another notable feature in Fig. 12 is that the predictability of monsoonal precipitation by the patch experiments (blue lines) decreases gradually with increasing lag, while that of the regression method (yellow lines) is somewhat irregular. This demonstrates that the patch-experimentbased method considers the dynamics and thus the reduction in skill is consistent with the persistence of the SSTs, while the skill of regression method is influenced by inherent sampling uncertainties.

Despite the robust results, this study has some limitations and further work is required to both understand fully and predict ASM precipitation variability. First, only the tropical SST-forced monsoon precipitation signal is addressed in the two models, but the SST-forced component of monsoonal precipitation variability accounts for (b) YHRV precipitation

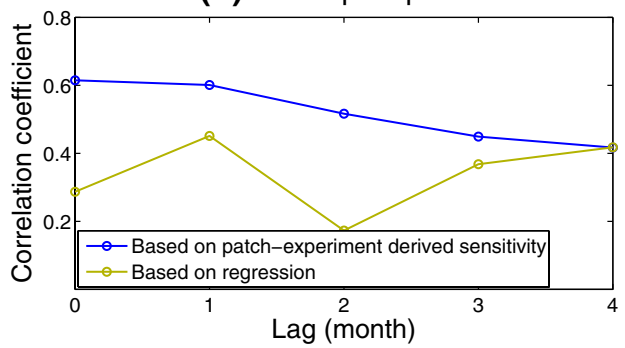

based (regression-based) sensitivity maps in the prediction. In the regression analysis, the training period was 1979-2011 and the prediction period was 1856-1978. The correlations were calculated over the prediction period only

only about $60 \%$ of the total precipitation variance over India and $40 \%$ over East China (as shown in Fig. 1). Second, the present results are all within the modeled world and therefore they suffer limitations related to the skill levels of current climate models. This is why all the reconstructions or predictions in this study were compared with the GOGA results instead of observations. The reality is that current climate models still cannot surpass the prediction skill of some empirical methods based on observational data (Newman 2013). In addition, the inherent lack of air-sea interaction in atmospheric GCMs might also affect the present results, especially over the Indian Ocean where SST responds strongly to radiation, rather than being generated by ocean dynamics. Although the veracity of the present results is confined by the above limitations, the value of this study is that with the aid of two models, it explores ASM sensitivities to SSTs from model perspective with alleviated signal-to-noise ratio. We believe that with the advancement of model skills in simulating the ASM, better understanding of ASM variability will be obtained by future studies using models that are more advanced.

Acknowledgments This work is supported by the Ministry of Science and Technology of China (National Basic Research Program of China 2012CB955603; 2012CB955200), the Strategic Priority Research Program of the Chinese Academy of Sciences (Grant No. XDA11010203), the Natural Science Foundation of China (Grant Nos. 41176006; 41221063; 41406001; 41476003), and the Fundamental Research Funds for the Central Universities (Grant Nos. 201413029; 201562030). The manuscript was improved by the constructive comments of four anonymous reviewers.

Open Access This article is distributed under the terms of the Creative Commons Attribution 4.0 International License (http://creativecommons.org/licenses/by/4.0/), which permits unrestricted use, distribution, and reproduction in any medium, provided you give appropriate credit to the original author(s) and the source, provide a link to the Creative Commons license, and indicate if changes were made. 


\section{References}

Bariffa KR, Jones PD, Wigley TML (1983) Climate reconstruction from tree rings: part I, basic methodology and preliminary results for England. Int J Climatol 3:233-242. doi:10.1002/joc.3370030303

Barsugli JJ, Sardeshmukh PD (2002) Global atmospheric sensitivity to tropical SST anomalies throughout the Indo-Pacific basin. J Clim 15:3427-3442

Barsugli JJ, Shin S-I, Sardeshmukh PD (2006) Sensitivity of global warming to the pattern of tropical ocean warming. Clim Dyn 27(5):483-492

Bookstein FL (1989) Principal Warps: thin-plate splines and the decomposition of deformations. IEEE Trans Pattern Anal Mach Intell 11:567-585

Chang C-P, Zhang Y, Li T (2000) Interannual and interdecadal variations of the East Asian Summer Monsoon and tropical Pacific SSTs. Part I: roles of the subtropical ridge. J Clim 13:4310-4325

Charney JG, Shukla J (1981) Predictability of monsoons. In: Lighthill J, Pearce RP (eds) Monsoon dynamics. Cambridge University Press, New York, pp 99-109

Chung CE, Ramanathan V (2006) Weakening of North Indian SST gradients and the monsoon rainfall in India and the Sahel. J Clim 19:2036-2045

Ding Y-H, Chan JCL (2005) The East Asian Summer Monsoon: an overview. Meteor Atmos Phys 89:117-142

Fan L, Shin S-I, Liu Q, Liu Z (2013) Relative importance of tropical SST anomalies in forcing East Asian Summer Monsoon circulation. Geophys Res Lett 40:2471-2477

Gadgil S, Kumar KR (2006) The Asian monsoon-agriculture and economy. In: Wang B (ed) The Asian monsoon. Springer-Praxis, New York, pp 651-683

Gill AE (1980) Some simple solutions for heat-induced tropical circulation. Q J R Meteorol Soc 106:447-462

Huang R, Sun F (1992) Impacts of the tropical western Pacific on the East Asian Summer Monsoon. J Meteorol Soc Jpn 70:243-256

Jonathan M, Goldberg MA (2001) Multiple regression analysis and mass assessment: a review of the issues. Apprais J 56:89-109

Kiehl JT, Hack JJ, Bonan GB, Boville BA, Williamson DL, Rasch PJ (1998) The national center for atmospheric research community climate model: CCM3. J Clim 11:1131-1149

Kistler R, Kalnay E, Collins W, Saha S, White G, Woollen J, Chelliah M, Ebisuzaki W, Kanamitsu M, Kousky V, van den Dool H, Jenne R, Fiorino M (2001) The NCEP-NCAR 50-year reanalysis: monthly means CD-ROM and documentation. Bull Am Meteorol Soc 82:247-268

Klein SA, Soden BJ, Lau NC (1999) Remote sea surface temperature variations during ENSO: evidence for a tropical atmospheric bridge. J Clim 12:917-932

Kumar A, Zhang Q, Peng P, Jha B (2005) SST-forced atmospheric variability in an atmospheric general circulation model. J Clim 18:3953-3967

Latif M, Barnett TP, Cane MA, Flügel M, Graham NE, von Storch H, Xu J-S, Zebiak SE (1994) A review of ENSO prediction studies. Clim Dyn 9:167-179

Lau N-C, Nath MJ (2000) Impact of ENSO on the variability of the Asian-Australian Monsoons as simulated in GCM experiments. J Clim 13:4287-4309

Li T, Wang B (2005) A review on the western North Pacific monsoon: synoptic-to-interannual variabilities. Terr Atmos Ocean Sci $16: 285-314$

Li SL, Lu J, Huang G, Hu KM (2008) Tropical Indian Ocean basin warming and East Asian Summer Monsoon: a multiple AGCM study. J Clim 21:6080-6088

Lu R (2001) Interannual variability of the summertime North Pacific subtropical high and its relation to atmospheric convection over the Warm Pool. J Meteorol Soc Jpn 79:771-783
Newman M (2013) An empirical benchmark for decadal forecasts of global surface temperature anomalies. J Clim 26:5260-5269

Nitta T (1987) Convective activities in the tropical western Pacific and their impacts on the Northern Hemisphere summer circulation. J Meteorol Soc Jpn 65:165-171

Parthasarathy B, Kumar RR, Kothawale DR (1992) Indian Summer Monsoon rainfall indices, 1871-1990. Meteorol Mag 121:174-186

Rasmusson EM, Carpenter TH (1983) The relationship between eastern equatorial Pacific Sea surface temperatures and rainfall over India and Sri Lanka. Mon Weather Rev 111:517-528

Rayner NA, Parker DE, Horton EB, Folland CK, Alexander LV, Rowell DP, Kent EC, Kaplan A (2003) Global analyses of sea surface temperature, sea ice, and night marine air temperature since the late nineteenth century. J Geophys Res 108(D14):4407. doi: 10.1029/2002JD002670

Roeckner E, Bäuml G, Bonaventura L, Brokopf R, Esch M, Giorgetta M, Hagemann S, Kirchner I, Kornblueh L, Manzini E, Rhodin A, Schlese U, Schulzweida U, Tompkins A (2003) The atmospheric general circulation model ECHAM5. Part I: model description. Report no 349. Max Planck Institute for Meteorology, Hamburg

Rowell DP (1998) Assessing potential seasonal predictability with an ensemble of multidecadal GCM simulations. J Clim 11:109-120

Rowell DP, Folland CK, Maskell K, Ward MN (1995) Variability of summer rainfall over tropical North Africa (1906-92): observations and modeling. Q J R Meteorol Soc 121:669-704

Shin S-I, Sardeshmukh PD (2010) Critical influence of the pattern of tropical ocean warming on remote climate trends. Clim Dyn. doi:10.1007/s00382-009-0732-3

Shin S-I, Sardeshmukh PD, Webb RS (2010) Optimal tropical sea surface temperature forcing of North American drought. J Clim 23:3907-3917.doi:10.1175/2010JCLI3360.1

Sperber KR (1999) Are revised models better models? A skill score assessment of regional interannual variability. Geophys Res Lett 26:1267-1270

Sperber KR, Palmer TN (1996) Interannual tropical rainfall variability in general circulation model simulations associated with the Atmosphere Model Intercomparison Project. J Clim 9:2727-2750

Tao SY, Chen LX (1987) A review of recent research on the East Asian Summer Monsoon in China. In: Chang CP, Krishnamurti TN (eds) Monsoon meteorology. Oxford University Press, New York, pp 60-92

Wang B, LinHo (2002) Rainy season of the Asian-Pacific Summer Monsoon. J Clim 15:386-396

Wang B, Wu R, Fu X (2000) Pacific-East Asian teleconnection: how does ENSO affect East Asian climate? J Clim 13:1517-1536

Wang B, Wu R, Lau K-M (2001) Interannual variability of the Asian Summer Monsoon: contrasts between the Indian and the western North Pacific-East Asian Monsoons. J Clim 14:4073-4090

Wang B, Ding Q, Fu X, Kang I-S, Jin K, Shukla J, Doblas-Reyes F (2005) Fundamental challenge in simulation and prediction of summer monsoon rainfall. Geophys Res Lett 32:L15711. doi:10. 1029/2005GL022734

Wang B, Wu Z, Li J, Liu J, Chang C-P, Ding Y, Wu G (2008) How to measure the strength of the East Asian Summer Monsoon. J Clim 21:4449-4463

Webster PJ, Yang S (1992) Monsoon and ENSO: selectively interactive systems. Q J R Meteorol Soc 118:877-926

Webster PJ, Magaña VO, Palmer TN, Shukla J, Tomas RA, Yanai M, Yasunari T (1998) Monsoons: processes, predictability, and the prospects for prediction. J Geophys Res 103:14451-14510. doi:10.1029/97JC02719

Weng H, Wu GX, Liu YM, Behera SK, Yamagata T (2011) Anomalous summer climate in China influenced by the tropical IndoPacific Oceans. Clim Dyn 36:769-782 
Wu R, Kirtman BP (2005) Roles of Indian and Pacific Ocean air-sea coupling in tropical atmospheric variability. Clim Dyn 25:155-170

Wu B, Li T, Zhou T (2010) Relative contributions of the Indian Ocean and local SST anomalies to the maintenance of the western North Pacific anomalous anticyclone during El Nino decaying summer. J Clim 23:2974-2986

Wu R, Chen J, Chen W (2012) Different types of ENSO influences on the Indian Summer Monsoon variability. J Clim 25:903-920

Xiang B, Wang B, Yu W, Xu S (2013) How can anomalous western North Pacific Subtropical High intensify in late summer? Geophys Res Lett 40:2349-2354. doi:10.1002/grl.50431

Xie P, Arkin PA (1997) Global precipitation: a 17-year monthly analysis based on gauge observations, satellite estimates, and numerical model outputs. Bull Am Meteorol Soc 78:2539-2558
Xie S-P, Hu K, Hafner J, Tokinaga H, Du Y, Huang G, Sampe T (2009) Indian Ocean capacitor effect on Indo-Western Pacific climate during the summer following El Niño. J Clim 22:730-747

Yang S, Lau K-M (1998) Influences of sea surface temperature and ground wetness on Asian Summer Monsoon. J Clim 11:3230-3246

Yang J, Liu Q, Xie S-P, Liu Z, Wu L (2007) Impact of the Indian Ocean SST basin mode on the Asian Summer Monsoon. Geophys Res Lett 34:L02708. doi:10.1029/2006GL028571

Zhou T, Gong D, Li J, Li B (2009) Detecting and understanding the multi-decadal variability of the East Asian Summer Monsoon? Recent progress and state of affairs. Meteorol Z 18:455-467 